Economia e Sociedade, Campinas, Unicamp. IE. http://dx.doi.org/10.1590/1982-3533.2021v30n3art08

\title{
Política industrial e redes de comércio de medicamentos: os casos do Brasil, Irlanda e Índia no período de 1995 a 2015 *
}

\author{
Kleber Alves da Silva Franculino ** \\ Rogério Gomes *** \\ Lia Hasenclever ${ }^{* * * * * * * * * * *}$
}

\begin{abstract}
Resumo
O patamar de desenvolvimento industrial das nações pode ser inferido pelo domínio tecnológico e produtivo de um país e da sua estrutura produtiva local. Estes elementos são também importantes para determinar a competitividade das nações e a sua participação no comércio internacional. O artigo avalia empiricamente como o desenvolvimento da indústria farmacêutica está associado às mudanças nos padrões de especialização na rede de comércio mundial de medicamentos para investigar a coevolução de tais dimensões tendo em vista o arcabouço das políticas industriais de três países distintos: Irlanda, Índia e Brasil. Os principais resultados, obtidos pelo método de Análise de Redes, mostram que Índia e Irlanda, diferente do Brasil, adotaram políticas mais consistentes e contínuas, essenciais para o sucesso de uma estratégia de desenvolvimento do setor, mensurado por seus papéis na rede de comércio mundial de medicamentos. Além disso, os resultados deixam evidente que a abertura comercial não é condição suficiente para um país alçar patamares superiores de competitividade.
\end{abstract}

Palavras-chave: Política industrial, Análise de redes, Comércio mundial de medicamentos, Indústria farmacêutica.

\begin{abstract}
Industrial policy and pharmaceutical trade networks: cases in Brazil, Ireland and India from 1995 to 2015

The level of industrial development of a nation can be inferred by the technological and productive domain of the country and its local productive structure. These elements are also important to determine the competitiveness of nations and their participation in international trade. The article empirically assesses how the development of the pharmaceutical industry is associated with changes in the patterns of specialization in the global medicines trade network to investigate the co-evolution of such dimensions in view of the industrial policy framework of three different countries: Ireland, India, and Brazil. The main results, obtained via the Network Analysis method, show that India and Ireland, unlike Brazil, have adopted more consistent and long-term policies, essential for the success of a sector development strategy, measured by their roles in the world trade network of medicines. Furthermore, the results make it clear that trade opening is not a sufficient condition for a country to reach higher levels of competitiveness.
\end{abstract}

Keywords: Industrial policy, Network analyses, Medicines world trade, Pharmaceutical industry.

JEL: O25, L65, F1.

\section{Introdução}

O desenvolvimento de uma estrutura produtiva mais avançada, entendido como o aprimoramento das competências e bases tecnológicas, e concomitante à elevação do valor

\footnotetext{
* Artigo recebido em 7 de fevereiro de 2020 e aprovado em 21 de julho de 2021.

** Doutorando do Instituto de Geociências da Universidade Estadual de Campinas (IG-Unicamp), Campinas, SP, Brasil. E-mail: kleber.franculino@gmail.com. ORCID: https://orcid.org/0000-0002-4634-3733.

${ }^{* * *}$ Professor da Universidade Estadual Paulista (Unesp), Araraquara, SP, Brasil. E-mail: rogerio.gomes@ unesp.br. ORCID: https://orcid.org/0000-0001-8469-7076.

***** Professora da Universidade Cândido Mendes (UCAM), Campos de Goytacazes, Rio de Janeiro, RJ, Brasil. E-mail: lia@ie.ufrj.br. ORCID: https://orcid.org/0000-0003-1384-6323.

${ }^{* * * * * *}$ Professora da Universidade Federal do Rio de Janeiro (UFRJ), Rio de Janeiro, RJ, Brasil.
} 
adicionado nas atividades econômicas locais, representou, durante muitas décadas, o objetivo central de diversas economias periféricas. Nesse sentido, diversos países procuraram, por meio de implementação de políticas industriais, desenvolver suas bases produtivas e, consequentemente, realizar a transformação estrutural de suas economias. O resultado foi, em geral, a alteração nos padrões nacionais de comércio e na inserção internacional que os caracteriza.

Com base nesse objetivo, determinadas indústrias foram reconhecidas como sendo estratégicas para o desenvolvimento econômico. A indústria farmacêutica, por ser responsável pela produção de bens essenciais à saúde da população e caracterizada como intensiva em ciência e tecnologia, foi objeto de diversas dessas políticas em vários países.

Este artigo (i) avalia empiricamente como o desenvolvimento da indústria farmacêutica está associado às mudanças nos padrões de especialização na rede de comércio mundial de medicamentos para (ii) investigar a coevolução de tais dimensões tendo em vista o arcabouço das políticas industriais de três países distintos: Irlanda, Índia e Brasil. Estes países são tomados como casos exemplares em virtude das distintas políticas, aplicadas ao longo do século XX para absorção/criação de competências voltadas ao desenvolvimento da indústria farmacêutica, que acabaram por refletir, posteriormente, na estrutura produtiva e desempenho comercial. No caso da Irlanda, as políticas priorizaram o investimento direto estrangeiro e, nos outros dois, Brasil e Índia, focaram no desenvolvimento local de competências. Assim, é pressuposto que as estratégias de desenvolvimento apresentam semelhanças e diferenças relevantes para explicar os resultados alcançados em termos de posicionamento na rede de comércio.

A literatura evolucionária entende que as políticas nacionais de desenvolvimento industrial contribuem para a transformação das indústrias e esta, por sua vez, pode ter reflexos nos padrões de comércio internacional. Este estudo segue essa compreensão: as bases técnico-produtivas podem ser alteradas em decorrência das mudanças nas competências (país e setor-específicas) fomentadas pelas políticas industriais e algumas delas (políticas e, portanto, competências) são mais efetivas ou bemsucedidas do que outras para se alcançar patamares superiores de competitividade no comércio internacional.

O desempenho do país na rede de comércio internacional é medido pelos indicadores de Análise de Redes aplicada sobre os fluxos de comércio exterior de medicamentos. Essa ferramenta fornece grafos - que neste estudo permitiu constatar a permanência de uma estrutura do tipo centroperiferia, ou seja, com os países mais desenvolvidos apresentando maior variedade de destinos de exportações de seus medicamentos - e indicadores quantitativos de rede, que possibilitam tanto discutir da estrutura da rede de comércio, quanto a comparar o desempenho ao longo dos anos dos países no mercado internacional. Assim, se os indicadores de um país evoluíram para uma posição da rede melhor que a anterior, pressupõe-se que as políticas de desenvolvimento adotadas e as competências desenvolvidas para a indústria farmacêutica nos anos anteriores podem ser consideradas bem-sucedidas.

Dosi e Soete (1988) defendem que estudos de comércio, para captar as alterações estruturais dos países, devem privilegiar os estudos setoriais ou específicos a determinadas indústrias, permitindo que a devida diferenciação de atividades econômicas seja feita e, com isso, seja possível captar diferentes potencialidades nacionais. É por estas razões que estudos relativos à adoção e 
implementação de políticas industriais (e a consequente transformação de uma indústria de um país) deveriam, necessariamente, ter como base a análise dos dados que representem o alvo específico dessas políticas. Com esse procedimento seria possível impedir que os resultados obtidos por uma atividade específica fossem mascarados por dados relativos ao desempenho geral da economia. Dessa maneira, é possível verificar a importância de um enfoque (meso)microeconômico tanto na elaboração quanto na avaliação de políticas de desenvolvimento.

Nesse contexto, este estudo subentende que para um conjunto de políticas ser capaz de surtir efeito na estrutura produtiva de um país, é necessário que sejam de longo prazo, com continuidade o suficiente para gerar transformações na capacitação produtiva e tecnológica nacionais, pois esse processo demanda tempo (Nelson; Winter, 1982). Isso implica que a análise dos resultados deva ocorrer em um período subsequente ao da implementação das políticas - a década de 1970 é admitida como marco na política industrial dos países estudados. Os resultados das políticas implementadas nesse período e ao longo da década de 1980 são verificados a partir dos anos 1990, quando se admite que as competências de absorção/criação pretendidas por essas políticas já estavam em vigor, momento em que diversos países realizaram sua abertura comercial. Nesse sentido, é suposto que os indicadores da rede de comércio aqui utilizados estão refletindo a capacidade dessas políticas de promoverem transformações na indústria farmacêutica nacional e, portanto, representando, em alguma medida, as competências adquiridas.

Ressalte-se que, para este estudo, a abertura comercial sem políticas anteriores que favoreçam as competências produtivas e tecnológicas, pode ser danosa à competitividade internacional do país. A abertura comercial em si pode ter efeitos distintos sobre uma economia, a depender do grau de desenvolvimento tecnológico já construído em períodos anteriores a ele.

O artigo está dividido em cinco seções, além desta introdução. Na seção 1 é feita uma breve revisão da literatura que trata das relações entre políticas industriais, competências tecnológicas e comércio internacional. A seção 2 descreve a indústria farmacêutica, destacando o papel da inovação e os diferentes tipos de produtos. Na seção 3 faz-se uma pequena resenha das políticas nacionais, isto é, as medidas adotadas por Brasil, Irlanda e Índia direcionadas ao desenvolvimento do setor farmacêutico. A metodologia, na seção 4, contém os conceitos essenciais de Análise de Redes. Na seção 5, são apresentados os resultados da análise das redes para o comércio global de medicamentos, destacando, na seção sete, os resultados para os países estudados. As considerações finais, destacam as características em comum das medidas que geraram os resultados mais significativos em termos de capacitação tecnológica na indústria farmacêutica.

\section{Comércio internacional, competências tecnológicas e políticas industriais}

Os fluxos de comércio internacional, enquanto indicadores importantes para revelar as competências e estrutura produtiva dos países, constituem objeto de estudo em diversas perspectivas teóricas. Os modelos tradicionais, que se sustentam fortemente em pressupostos estáticos como rendimentos constantes de escala e ausência de diferenças entre as técnicas produtivas dos países, têm sido substituídos por outras abordagens mais realistas (Lemme; Batista, 2013; Guimarães, 1997). Essa mudança de perspectiva implica, entre outras coisas, a necessidade de incorporar novos elementos na análise. Este estudo está sustentado na abordagem evolucionária que atrela políticas industriais, 
absorção de competências tecnológicas e desenvolvimento industrial - em particular, para países em desenvolvimento (Chang, 1994; Freeman, 1995; Lundvall, 1988; Mazzucato, 2013; Nelson, 1993).

A política industrial ${ }^{1}$ é um instrumento que pode contribuir para desenvolver habilidades no interior da firma e incentivar a criação, acesso e incorporação de competências tecnológicas (Chang, 1994; Suzigan; Furtado, 2006). Em particular, essas práticas podem promover transformações nas bases técnico-produtivas e aperfeiçoamentos nos produtos comercializados (Penrose, 1959) e aumentos de produtividade. Se esse processo for virtuoso, ou seja, se é construído por diferentes tipos de aprendizados (especialmente learning by doing e learning to learn ${ }^{2}$ ), as firmas (e a indústria) tendem a ser mais proativas e capazes de explorar as oportunidades presentes no ambiente (Andreoni, 2014; Cohen; Levinthal, 1990; Levinthal, 1996).

Em adição, se a incorporação das novas tecnologias emanadas das novas competências são melhores do que as antigas em termos de custos ou produtos originais, é muito provável que essas tecnologias passem a prevalecer no mercado em detrimento das últimas (Nelson; Winter, 1982). Se as vantagens advindas da incorporação das novas tecnologias têm dimensão internacional, os fluxos de comércio podem ser alterados (Dosi; Soete, 1988). Todavia, este processo não é um ato solitário, único, mas, ao contrário, em geral, é lento, dado que (i) a firma precisa, para adaptar-se às novas condições, alterar a sua própria cultura e organização (Nelson; Winter, 1982) e (ii) depende das interações e sinergias entre empresas e demais atores ("comunidade") que conformam o ambiente de inovação e de mercado (Levinthal, 1996). Em outras palavras, os atores e o próprio sistema coevoluem.

Em suma, os efeitos das políticas industriais sobre o desenvolvimento de competências no âmbito da firma, indústria local e vantagens competitivas no comercio exterior demandam tempo. Os países que dominam e desenvolvem competências tecnológicas específicas da indústria possuem posição relevante no comércio internacional. Amendola, Dosi e Papagni (1993) não só apontam o domínio de competências tecnológicas como um elemento primordial para explicar os fluxos de comércio no longo prazo como, também, criticam o uso de dados mais comumente utilizados, a exemplo de taxas de câmbio, preço e custos de produção, porque estariam limitados a uma análise de curto prazo. O grau de desenvolvimento tecnológico é um dos principais elementos da competitividade de um país e, uma vez que possui relação direta com sua estrutura produtiva, também irá refletir nos padrões de comércio de longo prazo do mesmo.

As inovações reestruturam o sistema produtivo e econômico e impulsionam o processo de desenvolvimento (Schumpeter, 1942). A busca contínua das empresas por inovações tecnológicas, que proporcionem lucros extraordinários e diferenciais de competitividade com relação aos concorrentes em um mercado, assume, portanto, a função de motor da economia capitalista, entendida como um sistema em constante transformação. Autores como Pavitt (1984), Marsili (2001), Malerba e Orsenigo (1997) e Castellacci (2008) distinguem diferentes tipos de indústrias de acordo com o seu padrão de inovação. Nas indústrias "baseadas em ciências", como a farmacêutica, as inovações

(1) Neste artigo, o conceito de política industrial é abrangente, incorporando a evolução de tecnologias, estruturas de empresas, instituições, marco regulatório e a política macroeconômica (Suzigan; Furtado, 2006).

(2) O sucesso de hoje constitui tanto uma nova tecnologia bem-sucedida, como um ponto de partida natural para as tecnologias de amanhã (Cohen; Levinthal, 1990). 
ocorrem de maneira acelerada (elemento central da competição capitalista) e, portanto, requerem acúmulo e permanente atualização das capacidades de absorção (Cohen; Levinthal, 1990). No mesmo sentido, Castaldi et al. (2009) consideram que os distintos desempenhos têm relação direta com a acumulação de competências tecnológicas, promovendo contínua desvantagem competitiva para os países tecnologicamente atrasados que carecem dessas competências.

Cimoli, Dosi e Stiglitz (2009) consideram que o desenvolvimento rumo ao catching up tecnológico ocorre por meio de um contínuo processo de aprendizado. Esse processo, entretanto, depende fundamentalmente da capacidade de aprendizado e de inovação dos países, o que implica na necessidade de construção de competências internas não derivadas unicamente da aquisição de bens de capital ou de know-how tecnológico (Bell; Pavitt, 1995). A competência inovativa de um país decorre do esforço inovativo endógeno e do posicionamento estratégico das empresas. Portanto, depende de dinâmicas tecnológicas próprias de cada país (Fagerberg, 1994). Entende-se que a construção dessas competências por parte das empresas demanda tempo e envolve elevada incerteza, inerente às atividades tecnológicas e inovativas e ao processo de reorganização das empresas. Assim sendo, políticas que visam incentivar e compensar esses esforços se mostram necessárias para o comprometimento das empresas no longo prazo.

Assim como Hasenclever et al. (2016), neste estudo não consideramos desenvolvimento como o resultado de simples ajustes macroeconômicos em direção ao equilíbrio. Entende-se que a ideia de desenvolvimento está relacionada à diferenciação entre os países concorrentes e à diversidade de atividades que as empresas desempenham nos territórios nacionais. Os países selecionados para esse estudo representam estratégias de desenvolvimento que demonstram semelhanças e diferenças relevantes para explicar os resultados alcançados em termos de posicionamento na rede de comércio.

Outro aspecto importante é que diversos autores apontam a relevância do estudo das firmas individuais sobre os fluxos de comércio de um país, uma vez que a decisão de investimento e produção é realizada por empresas privadas, mais do que por governos nacionais. Contudo, apesar das decisões empresariais influenciarem diretamente os desempenhos nacionais, o ambiente criado pelas decisões de governo, mais especificamente sobre políticas de fomento e desenvolvimento das indústrias, cria um sistema sob o qual as firmas individuais estarão submetidas para tomar suas decisões, de acordo com Dunning (1995):

... the way in which governments organize the resources, capabilities, and markets within their jurisdiction (this includes the extent to which they are prepared to delegate this responsibility to private hierarchies, groups of firms, or markets) is a critical determinant of the pattern of international transactions (Dunning, 1995, p. 189).

Desse modo, a avaliação dos desempenhos nacionais não deveria se limitar à análise das firmas individuais, mas considerar a influência dos ambientes institucional, econômico e de negócios criados pela interação das políticas nacionais com o ambiente regulatório estabelecido a nível internacional, por organizações, acordos e tratados realizados pelas nações e por instituições supranacionais.

Assim, as políticas implementadas devem considerar as características locais, de maneira a utilizar potencialidades e lidar com problemas que podem não ter sido previstos em modelos e desenhos de política elaborados para outras regiões ou países. Nesse sentido, vemos que a adoção de 
estratégias e as políticas distintas de desenvolvimento são as responsáveis pela obtenção de diferentes resultados em termos de desenvolvimento industrial (Hasenclever; Paranhos, 2008) e, consequentemente, em termos de desempenho no comércio internacional.

Enfim, as diferenças internacionais observadas no padrão de comércio, grupos de destinos e origens das importações, tipos e volumes de produtos comercializados, grau de integração comercial e posicionamento relativo na rede de comércio exterior dependem fundamentalmente da capacidade de absorver, adaptar, gerar e desenvolver tecnologias, competências essas que dependem das decisões estratégicas das empresas, mas que são também influenciadas por políticas elaboradas e implementadas por governos nacionais.

\section{Características da indústria farmacêutica: inovação e tipos de produto}

A indústria farmacêutica é responsável pelo desenvolvimento e produção de medicamentos para uso humano e animal. Trata-se de uma atividade intensiva em ciência e tecnologia, além de complexa e interdisciplinar por sua própria natureza, envolvendo conhecimentos relativos à química, farmacologia, microbiologia, e biologia molecular, entre outros (Drews; Ryser, 1997). A inovação determina a dinâmica competitiva nessa indústria (Hasenclever et al., 2010; Vieira; Ohayon, 2006), de modo que o lançamento contínuo de novos e melhorados produtos e processos permite que a empresa inovadora, quase sempre por meio de uma patente, usufrua e explore economicamente sua inovação de maneira exclusiva.

Trata-se, portanto, de uma indústria com inovações caracterizadas pela alta cumulatividade de conhecimentos que garantem elevados níveis de apropriabilidade e oportunidade inovativa relativamente alta pois está baseada em ciência. Essas características acabam por dificultar a entrada de novas empresas inovadoras e concentram as inovações em poucas empresas de grande porte, que possuem competências tecnológicas e organizacionais acumuladas, atuam e competem a nível mundial. Assim, como essas empresas lideram o setor e atuam de maneira globalizada, o mercado também fica concentrado no plano internacional. A liderança de mercado é exercida em segmentos de mercado particulares, mediante estratégia de diferenciação de produtos. A competição via diferenciação, somada a interdependência nas estratégias seguidas pelas empresas, acabam por definir a estrutura de mercado como um oligopólio diferenciado (Canchumani, 2009; Hasenclever et al., 2010).

Uma das possíveis formas de estudar os produtos dessa indústria é estabelecer uma relação entre o tipo de inovação e o grau de novidade do conhecimento tecnológico. Inovações radicais têm conteúdo de conhecimento e tecnologia novos, podem ser patenteadas e tem preços mais elevados durante a vigência das patentes. Inovações incrementais, por sua vez, são o resultado de melhorias em produtos e processos já existentes e embutem menor grau de conhecimento tecnológico novo. $\mathrm{O}$ primeiro tipo de inovação garante uma competitividade maior para concorrer no comércio internacional uma vez que representam uma novidade para o conjunto dos mercados e não somente para o mercado local. Dessa forma, pode-se supor que existe uma relação entre o grau de inovação que a indústria de um país é capaz de realizar e sua posição na rede de comércio internacional.

O Quadro 1 procura ilustrar essas relações, partindo do grau mais baixo de inovação (incremental) até o nível mais complexo de inovação (radical), a partir da rota da síntese química. Os 
países com maior domínio tecnológico (fortemente concentrados nas economias desenvolvidas, onde se situam as sedes das grandes empresas e boa parte das pesquisas, especialmente de fase 1 e 2 ) possuem capacidade de atuar em todos os graus de inovação, estão mais aptos a acessar as oportunidades tecnológicas e têm relevante posição no comércio internacional. Países com menor competência tecnológica também realizam atividades inovativas, mas se concentram na produção de inovações incrementais, como é o caso da Índia, altamente especializada em medicamentos genéricos, e do Brasil.

Quadro 1

Tipos e graus de inovação na indústria farmacêutica

\begin{tabular}{|l|c|}
\hline \multicolumn{1}{|c|}{ Tipo } & Grau \\
\hline Novo fármaco & Invenção \\
\hline Novo medicamento & Radical \\
\hline Novo alvo & Incremental \\
\cline { 1 - 1 } Novas associações & \\
\hline Genérico ou similar & \\
\hline
\end{tabular}

Fonte: Elaboração dos autores com base em Vieira e Ohayon (2006) e Santoro (2000).

Conforme Vieira e Ohayon (2006), a inovação incremental envolve a utilização de entidades químicas já conhecidas para novos usos (novo alvo), novas associações, e novas formulações. O medicamento genérico é uma cópia equivalente (bioequivalência e biodisponibilidade equivalentes) de um medicamento cuja patente é expirada, e o similar pode conter melhoramentos. A elaboração de um novo fármaco é considerada uma invenção, uma vez que ainda não compõe um medicamento comercializado, enquanto o novo medicamento (ou de referência), isto é, o produto finalizado explorado comercialmente, representa a inovação radical, o grau mais elevado de inovação por conter conhecimento novo - o fármaco inventado.

Medicamentos podem ser de referência, genéricos, similares e OTC (over the counter). Cada tipo de produto possui uma lógica própria de pesquisa e desenvolvimento (P\&D), comercialização, estratégia de marketing e padrão de competição. Dentre esses, o tipo mais rentável é o dos medicamentos de referência. Resultado de um longo processo de P\&D e elevados investimentos, o medicamento de referência pode ser protegido por uma patente, garantindo direitos exclusivos ao inovador. Os medicamentos de referência também são conhecidos por sua marca, que após o vencimento das patentes lhes permite manter liderança no mercado.

Os genéricos, por sua vez, precisam ser equivalentes aos de referência e podem ser produzidos sem a licença da empresa proprietária do mesmo, uma vez que a patente deste medicamento já expirou. Embora também exijam considerável competência tecnológica para sua produção, os custos envolvidos nas atividades de $\mathrm{P} \& \mathrm{D}$ do genérico são menores, uma vez que os testes clínicos, a fase mais custosa da pesquisa, não precisam ser replicados. Os preços de entrada no mercado dos medicamentos genéricos são regulados e devem ser mais baixos do que o preço dos medicamentos de referência, o que contribui substancialmente para que este tipo de medicamento siga um padrão de competição distinto. Além disso, esse medicamento é comercializado somente com 
a denominação genérica do princípio ativo. Os similares, assim como os genéricos, podem ser considerados "cópias" do medicamento de referência, mas não são equivalentes. O similar pode diferir em tamanho, forma, prazo de validade, embalagem, rotulagem, excipiente e veículo, sendo identificado por nome comercial ou marca (Anvisa, 2017).

Por fim, os medicamentos OTC são utilizados para tratamentos simples que não exigem acompanhamento médico, o que faz com que possam ser vendidos também em outros tipos de varejos que não as farmácias e drogarias, especializadas na venda de medicamentos. Em resumo, os OTC diferem dos medicamentos de referência, similares e genéricos que, muitas vezes, exigem prescrição médica para serem comercializados e a sua venda é feita somente no comércio especializado.

A compreensão das diferenças entre os tipos de medicamentos é importante porque permite relacionar os países e seus respectivos patamares de desenvolvimento industrial com os padrões identificados na elaboração das redes de produção e comércio. Como mencionado acima, países com maior grau de desenvolvimento conseguem atuar nas etapas da cadeia de valor farmacêtica mais densas em conhecimento e comercializar produtos de maior valor agregado (medicamentos de referência).

\section{Políticas nacionais para a indústria farmacêutica: Brasil, Índia e Irlanda}

Apesar da existência de diversas formas de política industrial e de distintos matizes teóricos para conceituá-la, neste artigo fazemos um breve levantamento do histórico de políticas adotadas pelos países a partir de uma perspectiva evolucionária. Isso implica em priorizar o estudo das medidas voltadas para o aprendizado tecnológico (inovativo) e acumulação de competências produtivas e organizacionais no interior das firmas. O objetivo dessas políticas é estimular a inovação, motor do desenvolvimento econômico (Schumpeter, 1942) e a capacidade competitiva das empresas, pautada por um processo evolutivo, contínuo de aquisição de competências tecnológicas (Nelson; Winter, 1982).

As políticas industriais, portanto, são definidas de modo abrangente, incluindo políticas de comércio, de ciência e tecnologia, ações que visam atuar sobre o investimento direto estrangeiro, os direitos de propriedade intelectual e a alocação de recursos financeiros (Cimoli; Dosi; Stiglitz, 2009; Ferraz; Paula; Kupfer, 2013). Não se trata de um conjunto isolado de medidas, mas de ações que consideram o ambiente institucional, os mecanismos de mercado, o grau de desenvolvimento dos países e seus respectivos padrões tecnológicos. A coordenação da política industrial seria um conjunto de medidas ex-ante, elaboradas para a criação do ambiente institucional capaz de moldar regras de comportamento e aprendizado sob as quais os mecanismos econômicos operam (Suzigan; Furtado, 2006).

Os países estudados se inserem em estratégias distintas de desenvolvimento, visando segmentos específicos e alcançando graus diferentes de competência inovativa. Os distintos graus de desenvolvimento possuem relação direta com as diferentes escolhas de políticas, conforme sugerido por Hasenclever e Paranhos (2013) para os casos da Índia e do Brasil quando constataram uma relação entre as políticas adotadas e o grau de desenvolvimento industrial alcançado após a abertura comercial dos anos 1990. 
Neste artigo, as políticas industriais adotadas pelos três países foram observadas a partir de cinco dimensões: 1) a continuidade e flexibilidade nas políticas, como uma forma de verificar a capacidade que os países demonstraram de manter os eixos elementares que nortearam sua estratégia de desenvolvimento, ao mesmo tempo em que foram capazes de modificar o desenho e a forma de intervenção de acordo com as respostas dos agentes; 2) o momento e a forma como os países estudados realizaram abertura comercial, visto que os três praticavam a política de substituição de importações, em períodos distintos do século XX; 3) a relação estabelecida com as empresas multinacionais, dentro da estratégia de desenvolvimento industrial dos três países; 4) o gerenciamento do regime de propriedade intelectual, importante fator no tocante às possibilidades de aprendizado tecnológico e; 5) quais e como foram as políticas implementadas que visavam especificamente as empresas de capital nacional, qual foi o papel atribuído a essas empresas na agenda de desenvolvimento industrial. Os itens a seguir exploram, segundo os critérios acima, as diferenças nas políticas adotadas pelos três países selecionados por este estudo, de maneira a relacionar as estratégias de políticas adotadas e os resultados obtidos em termos de estrutura produtiva.

\subsection{Brasil}

Apesar de as décadas de 1970 e 1980 terem sido períodos de implementação de uma série de políticas que visavam o desenvolvimento de uma indústria farmacêutica nacional, alguns fatores acabaram prejudicando o resultado dessas políticas. Além da instabilidade macroeconômica ocorrida durante a década de 1980 (Guennif; Ramani, 2012), a descontinuidade nas políticas de ciência e tecnologia e cortes orçamentários em instituições de pesquisa dificultaram o processo de tomada de decisões de longo prazo por parte das empresas, especialmente aquelas relacionadas a atividades de P\&D. Conforme Suzigan e Furtado (2006), nessas circunstâncias a política industrial perde potencial e vigor, o que reforça, mais uma vez a necessidade de interpretação de política industrial a partir de uma perspectiva ampla, isto é, que também contemple as condições macroeconômicas nacionais.

Contudo, apesar das dificuldades observadas na década de 1980, foi durante o início da década de 1990 que se impuseram as rupturas mais radicais em relação à condução da política industrial, o que ocorreu por duas vias. A primeira foi a abrupta abertura econômica que o Brasil realizou, que impulsionou a importação de intermediários por parte de empresas nacionais e multinacionais, acarretando o fechamento de unidades produtivas desses insumos em território nacional. A segunda ruptura foi o abandono deliberado das políticas industriais que vinham sendo praticadas até então.

Esse novo cenário, combinado com a baixa competitividade das empresas nacionais, acabou por resultar em fortes e crescentes déficits na balança comercial do setor, inicialmente pela importação de insumos e, mais recentemente, também pela importação de medicamentos acabados. Diante da abertura econômica, as empresas multinacionais instaladas no Brasil passaram a desverticalizar a produção local e a importar os seus insumos, no que foram seguidas pelas empresas nacionais inclusive aquelas produtoras de genéricos. Essas empresas exploravam o mercado interno sem exportar ou desenvolver atividades de maior valor agregado em território nacional.

No Brasil, desde a implementação do Código de Propriedade Industrial em 1971, as empresas brasileiras utilizavam a cópia das empresas inovadoras para produção de medicamentos já existentes. 
Essa possibilidade se estendeu com a regulamentação dos medicamentos similares em 1978 (Torres, 2015). Ademais, o aprendizado tecnológico das empresas brasileiras durante a década de 1970 e 1980 foi essencialmente passivo, suficiente apenas para imitar as inovações das multinacionais.

Na década de 1990, a promulgação da nova lei de propriedade intelectual para regular o regime de propriedade intelectual no Brasil, de acordo com as novas regras do TRIPS (Trade-Related Aspects of Intellectual Property Rights), interrompeu a possibilidade das empresas nacionais de utilizar reengenharia para promoverem seu desenvolvimento tecnológico. O período de transição entre a antiga e a nova Lei introduziu o mecanismo conhecido como pipeline, que permitia a concessão de patentes para inovações de maneira retroativa, isto é, um medicamento que possuísse patente em outro país recebia automaticamente proteção patentária no Brasil. Este foi um procedimento diferente do mecanismo mailbox implementado pela Índia, que previa um período de 10 anos para adequação ao novo regime de propriedade intelectual (Hasenclever et al., 2010).

Contudo, uma janela de oportunidade para as empresas de capital nacional foi aberta com a Lei dos Genéricos de 1999. Por meio dessa lei, empresas brasileiras passaram a se especializar nesse segmento, com algumas obtendo expressivos resultados comerciais e considerável espaço no mercado doméstico.

\section{2 Índia}

A Índia, diferente do Brasil, apresenta capacidade de manter suas políticas industriais ao longo do tempo. Como exemplo, verifica-se a manutenção dos chamados Planos Quinquenais desde a década de 1950. Nesses planos as políticas são direcionadas para setores específicos, sendo que a indústria farmacêutica foi incluída já no segundo Plano Quinquenal, em 1956 (Nassif, 2006). Também demonstra flexibilidade, uma vez que os Planos Quinquenais preveem avaliações e alterações no seu funcionamento a cada cinco anos. Contudo, apesar de ter a indústria farmacêutica como um dos alvos de políticas, a Índia passou por uma severa crise de abastecimento de medicamentos essenciais no final da década de 1960, o que induziu o governo a estimular a produção nacional de medicamentos.

Para isso, o governo indiano adotou uma série de medidas. Entre elas, a elaboração e implementação da Lei de Patentes de 1970 (que não reconhecia patente de uma série de produtos, incluindo medicamentos), a FERA (Foreign Exchange Regulation) que visava controlar o capital estrangeiro em indústrias estratégicas e a DPCO (Drug Price Control Order), que visava acompanhar a evolução dos preços dos medicamentos por meio de controle indireto (Ray, 2009). Dessa forma, a Índia optava, claramente, pela priorização das empresas de capital nacional em detrimento das empresas estrangeiras por meio de forte controle sobre a participação acionária estrangeira nas empresas instaladas localmente.

O mercado indiano, assim como o brasileiro, era protegido por tarifas de importação até o início dos anos 1990, resultado da política de substituição de importações. Contudo, mesmo protegido, havia estímulo ao esforço inovativo. A combinação da política de controle de preços com o regime de propriedade intelectual permissivo, dada a Lei de Patentes de 1970, explica, em parte, os esforços endógenos de capacitação. A DPCO previa que os medicamentos que comprovassem ser produzidos em território indiano desde o estágio inicial estariam livres do controle de preços por um período de cinco anos (Felker; Chaudhuri; Gyorgy, 1997). Desse modo, as empresas indianas se capacitaram a 
produzir medicamentos e alguns princípios ativos, permitindo à Índia ser exportadora de produtos farmacêuticos já na década de 1980 .

Um fato extremamente importante para as empresas indianas foi a promulgação da Lei HatchWaxman, em 1984, nos Estados Unidos, que tinha como objetivo elevar a acessibilidade a medicamentos e diminuir custos com saúde. Essa lei, que substituiu os requerimentos de testes clínicos para medicamentos genéricos por testes mais simples, de bioequivalência e biodisponibilidade, representou uma importante oportunidade para a indústria indiana em um grande mercado consumidor. De fato, com a abertura comercial dos anos 1990, a Índia passou a exportar medicamentos para países desenvolvidos, em especial os Estados Unidos. A combinação de capacitação produtiva adequada às boas práticas de fabricação (aprovadas pelo FDA), medicamentos mais baratos pela especialização em genéricos e um mercado relevante, possibilitaram exportações significativas de medicamentos pelas empresas indianas (Guennif; Ramani, 2012).

Assim, a abertura comercial potencializou as exportações indianas. Isso ocorreu, contudo, devido à construção de competências produtivas e tecnológicas em um período anterior, resultado de um conjunto de políticas de estímulo com respostas apropriadas das empresas privadas e públicas, e não como uma resposta natural à abertura ao mercado internacional.

\subsection{Irlanda}

A Irlanda seguiu um modelo de desenvolvimento distinto da Índia, baseado na atração de capital estrangeiro desde 1950. No entanto, diferente do Brasil, que também atraiu capital estrangeiro na década de 1950, foi capaz de conduzir alterações na sua política industrial quando os resultados alcançados estiveram aquém dos desejados.

Durante a década de 1980, a Irlanda sofria com uma grave crise de desemprego e pobreza, resultado da abertura econômica que foi acelerada na década de 1970, especialmente com a entrada do país na Comunidade Econômica Europeia em 1973. As dificuldades enfrentadas pelas empresas irlandesas para competir com as importações acabaram por eliminar uma grande quantidade de firmas e postos de trabalho. Por outro lado, a Irlanda passou a ter acesso ao mercado europeu, o que foi um fator determinante para a atração de empresas multinacionais ao país (Paus, 2005).

Para lidar com esses problemas, a Irlanda promoveu modificações substanciais em sua política industrial. Em 1982 foi elaborado o Relatório Telesis, da consultoria Telesis Consulting Group, que apontava para a necessidade de alterações na forma como os incentivos governamentais eram concedidos. Os projetos que deveriam receber prioridade no recebimento desses incentivos deveriam ter como características a alocação de atividades-chave na Irlanda, empregando mão-deobra qualificada e, em especial, com empresas locais como fornecedoras (Bastian, 2008). Em 1984, o White Paper on Industrial Policy lançado pelo governo declarava como objetivo principal a geração de empregos, mantendo a política de atração de multinacionais (Fitzpatrick, 2001).

Na esteira da nova orientação da política industrial irlandesa, foram estabelecidos o Programa de Desenvolvimento de Empresas e o Programa Nacional de Encadeamento Produtivo, em 1985. Em seguida, foram lançadas a Lei de Desenvolvimento Industrial e a Lei de Ciência e Tecnologia. Essas novas orientações da política industrial irlandesa visavam o estímulo da indústria nacional, sem, no 
entanto, abandonar a política de atração de multinacionais. Desse modo, a Irlanda permaneceu como um dos principais destinos de investimento das empresas estrangeiras, atraídos, sobretudo, (i) pela proximidade e facilidade de ingresso no mercado europeu, mas também pelas (ii) boas condições proporcionadas pelas políticas de incentivo, a (iii) mão de obra qualificada (e relativamente barata) e (iv) o idioma nacional.

Quadro 2

Diferenças nas políticas implementadas pelos três países

\begin{tabular}{|c|c|c|c|}
\hline \multirow{2}{*}{ Critério de Avaliação } & \multicolumn{3}{|c|}{ País } \\
\hline & \begin{tabular}{|c|} 
Brasil \\
\end{tabular} & Índia & Irlanda \\
\hline $\begin{array}{l}\text { Continuidade e flexibilidade da } \\
\text { política industrial }\end{array}$ & $\begin{array}{l}\text { Inconstância e descontinuidade, com } \\
\text { política industrial submissa à política } \\
\text { macroeconomica. }\end{array}$ & $\begin{array}{l}\text { Continuidade de políticas desde a década } \\
\text { de 1950, com atualizações e mudanças } \\
\text { de acordo com os Planos Quinquenais. }\end{array}$ & $\begin{array}{l}\text { Continuidade e flexibilidade, realizando duas } \\
\text { grandes revisões da política industrial, em } 1980 \text { e } \\
\text { 1991. Ao mesmo tempo, manteve elementos } \\
\text { essenciais: geração de empregos e atração de } \\
\text { IDE. }\end{array}$ \\
\hline $\begin{array}{l}\text { Abertura ao comércio } \\
\text { internacional }\end{array}$ & $\begin{array}{l}\text { Proteção ao mercado interno. } \\
\text { Abrupta abertura comercial (década } \\
\text { de 1990), que incentivou substituição } \\
\text { de produção local por importações. }\end{array}$ & \begin{tabular}{|l|} 
Proteção ao mercado interno com \\
capacitação das empresas. Com a \\
abertura, o país passou a exportar \\
medicamentos para países desenvolvidos, \\
em especial para os Estados Unidos.
\end{tabular} & $\begin{array}{l}\text { Em determinados momentos foi causa de crises } \\
\text { internas (abrupta abertura em 1973, com a } \\
\text { entrada na CEE), mas, posteriormente, propiciou } \\
\text { acesso a mercados visados pelas empresas } \\
\text { multinacionais. }\end{array}$ \\
\hline $\begin{array}{l}\text { Relação com Empresas } \\
\text { multinacionais }\end{array}$ & $\begin{array}{l}\text { Empresas multinacionais voltadas } \\
\text { principalmente mercado interno. }\end{array}$ & $\begin{array}{l}\text { Restringe atuação das empresas } \\
\text { multinacionais com forte controle sobre a } \\
\text { participação acionária estrangeira. }\end{array}$ & $\begin{array}{l}\text { Estratégia de industrialização baseada na atração } \\
\text { de empresas multinacionais com orientação } \\
\text { exportadora, seguida de políticas de estímulo às } \\
\text { relações entre empresas. domésticas e } \\
\text { estrangeiras. }\end{array}$ \\
\hline Propriedade intelectual & $\begin{array}{l}\text { Adequação imediata ao acordo } \\
\text { TRIPS sem considerar o estágio de } \\
\text { desenvolvimento da indústria } \\
\text { nacional }\end{array}$ & $\begin{array}{l}\text { Utilizou os mecanismos de transição } \\
\text { previsto no acordo TRIPS para priorizar a } \\
\text { capacitação tecnológica doméstica. }\end{array}$ & $\begin{array}{l}\text { Adequação ao acordo TRIPS, compondo o quadro } \\
\text { de incentivos de atração de multinacionais. }\end{array}$ \\
\hline $\begin{array}{l}\text { Políticas para o capital } \\
\text { nacional }\end{array}$ & $\begin{array}{l}\text { Após severa descontinuidade das } \\
\text { cadeias produtivas com a abertura } \\
\text { comercial, a Lei dos Genéricos } \\
\text { (1999) cria janela de oportunidade } \\
\text { para empresas nacionais. }\end{array}$ & $\begin{array}{l}\text { Priorização das empresas domésticas } \\
\text { pelo menos desde a década de } 1970 \text {, } \\
\text { com incentivos a atividades de P\&D. }\end{array}$ & $\begin{array}{l}\text { Políticas elaboradas para o desenvolvimento de } \\
\text { empresas domésticas em conjunto com MNC's. } \\
\text { No início dos anos 1990, a política industrial é } \\
\text { reorientada para enfatizar a capacitação inovativa } \\
\text { doméstica, e em } 1998 \text { é criada a Enterprise } \\
\text { Ireland, para atender as necessidades das } \\
\text { empresas nacionais. }\end{array}$ \\
\hline
\end{tabular}

Fonte: Elaboração dos autores com base na literatura consultada.

\section{Metodologia}

A literatura referente à aplicação de redes para análise do comércio internacional vem apresentando crescimento considerável nos últimos anos. As métricas de rede, diferentemente de indicadores mais tradicionais de comércio, têm o potencial de apontar tanto a estrutura (topologia) como as relações existentes e padrões de interatividade entre diferentes elementos que compõem todo o conjunto de países participantes do comércio internacional. Por meio dessas métricas, é possível verificar a influência que diferentes países exercem entre si e sobre toda a rede (De Benedictis et al., 2014), os padrões de clusterização e conectividade dos parceiros comerciais (Lee et al., 2013), o grau de integração de blocos econômicos ou países individuais em relação à economia regional e mundial (Reyes; Schiavo; Fagiolo, 2010), além de outros fenômenos emergentes da interação dos elementos que compõem a rede.

Os diversos estudos realizados sobre redes de comércio utilizam uma grande variedade de metodologias e de tratamento de dados. De maneira geral, a Análise de Redes aplicada ao comércio tende a utilizar dados agregados de exportação ou importação, não diferenciando setores ou indústrias. Além disso, é comum a retirada de determinados fluxos ou países que estejam abaixo de um determinado valor, como forma de destacar as interações mais relevantes. Conforme Kandogan 
(2017), os tratamentos de dados acabam por alterar, por vezes substancialmente, o resultado das métricas, tanto em termos de indicadores da rede em geral, como para as medidas de centralidades específicas dos nós (países).

Para uma análise mais apurada da topologia da rede de comércio, este estudo segue a metodologia de Kandogan (2017), o que envolve: 1) não excluir da rede nenhum país, mesmo os que forem pouco representativos em termos de conexões (grau) e volume comercializado; 2) usar dados de importação, dado que há certa tendência de que esses fluxos sejam mais exatos do que os de exportação; 3) empregar de dados desagregados (nesse estudo, dados referentes ao comércio de medicamentos) e; 4) utilizar ligações com intensidades inferidas a partir dos volumes comercializados, em vez de considerar somente a existência ou não de relação comercial entre os países da rede.

A metodologia deste estudo adota dois tipos de tratamento das informações, ambas resultantes da análise de redes por meio da aplicação do software Gephi aos dados do comércio. O primeiro é o estudo das posições relativas dos países na rede de comércio internacional, o que implica em uma análise visual da rede (grafos). Para isso, o algoritmo de distribuição Force Atlas 2 é sobreposto aos dados de comércio. Essa distribuição simula um sistema físico para realizar a distribuição dos nós (países) em uma rede (todo o comércio de medicamentos) a partir de uma lógica de atração, causadas pela força de suas conexões (volumes comercializados), e repulsão, causada pelo grau dos nós (número de ligações ou parceiros comerciais que um país possui na rede) (Jacomy et al., 2014).

Desse modo, a distribuição utilizada para a elaboração dessa rede, a Force Atlas 2, utiliza o peso das arestas ( $p$ - valores de importação) para aproximar os nós (países) e o grau (número de conexões) dos nós para afastá-los. A força de atração $\left(\mathrm{F}_{\mathrm{a}}\right)$ e a força de repulsão $\left(\mathrm{F}_{\mathrm{r}}\right)$ entre dois nós ( $\mathrm{n}_{1}$ e $\mathrm{n}_{2}$ ) são definidas por:

$$
F_{a}\left(n_{1}, n_{2}\right)=p\left(n_{1}, n_{2}\right) \quad F_{r}\left(n_{1}, n_{2}\right)=k_{r} \frac{\left(g\left(n_{1}\right)+1\right)\left(g\left(n_{2}\right)+1\right)}{p\left(n_{1}, n_{2}\right)}
$$

Onde:

$p=$ peso da aresta (neste trabalho, o fluxo comercial)

$g=$ grau (ou número de parceiros comerciais)

$\mathrm{k}_{\mathrm{r}}=$ dimensionamento (coeficiente de repulsão, selecionado durante a elaboração do grafo, para obter maior ou menor dispersão ${ }^{3)}$

$\left(\left(n_{1}\right)+1\right)=$ permite que mesmo nós com grau 0 possuam alguma força de repulsão.

O algoritmo de distribuição Force Atlas 2 foi selecionado para este estudo porque as suas propriedades representam bem uma lógica hierárquica de rede: os países responsáveis pela maior parcela do comércio mundial de medicamentos ficam posicionados no centro e os menos relevantes são situados às margens da rede. Como a posição de cada país é influenciada pelos outros, a disposição dos países na rede é capaz de revelar o papel que cada um exerce nessa rede.

O segundo tipo de análise se baseia no cálculo dos indicadores quantitativos de rede, que permitem a comparação do desempenho entre países no mercado internacional ao longo dos anos.

(3) Essa variável foi mantida constante ao longo dos anos para os diferentes grafos de Force Atlas 2. 
Esta classe de indicadores é aqui dividida em dois grupos. O primeiro, relativo às medidas relacionadas às redes de comércio em geral: densidade da rede - razão entre número de ligações existentes e todas aquelas que poderiam existir; grau médio - número médio de conexões; diâmetro - representa a maior distância de toda a rede entre dois nós; modularidade - mensura a densidade das conexões existentes dentro das comunidades em comparação com as ligações existentes entre as comunidades (Blondel et al., 2008) - varia no intervalo [-1, 1].

O segundo grupo de indicadores quantitativos de redes é relativo às métricas utilizadas nos três países objetos deste estudo: centralidade de grau de entrada - número de origens das importações de determinado país - e de saída - número de destinos das exportações de um país; clusterização - a tendência de formação de blocos comerciais. Centralidade diz respeito ao quão importante (central) um nó (país) é de acordo com um critério específico. Uma elevada centralidade de grau implica que o país em questão possui um nível de conectividade elevado, ou seja, alta ligação ou integração com outros elementos da rede (Reyes; Schiavo; Fagiolo, 2010). Assim, esses dois indicadores (centralidade e clusterização) são calculados para os nós individuais em uma rede, enquanto os demais (grau médio, diâmetro, densidade de modularidade) revelam padrões da rede como um todo, permitindo verificar a evolução do mercado internacional de maneira geral, e como os países selecionados se posicionam dadas as mudanças ocorridas ao longo dos anos.

Neste artigo, são calculados:

- grau de saída do país j - número de destinos das exportações do país j;

- grau de saída ponderado de $\mathrm{j}$ - o valor das exportações de $\mathrm{j}$ com relação ao total de exportações no mundo;

- grau de entrada do país j - número de origens das importações feitas pelo país j;

- grau de entrada ponderado de $\mathrm{j}$ - o valor das importações de $\mathrm{j}$ com relação ao total de importações no mundo;

- grau médio da rede - número médio de conexões de uma rede;

- diâmetro - maior dos menores caminhos entre dois nós;

- densidade - proporção entre as conexões (elos entre países) existentes e as possíveis;

- modularidade - mensura a densidade das conexões existentes dentro das comunidades em comparação com as ligações existentes entre as comunidades ${ }^{4}$.

Um número elevado de grau de saída (destinos de exportações) indica uma aguda postura exportadora. Em uma indústria altamente regulada como a farmacêutica, isso indica uma forte capacidade competitiva, tanto no sentido de manter presença no mercado internacional, quanto no sentido de lidar com distintos regimes regulatórios nacionais. Nesse sentido, conhecer essas métricas não basta: torna-se necessário verificar quais são as origens e destinos desses produtos. Pretende-se fazer um comparativo entre as redes e as suas métricas, focando nos países selecionados para este estudo.

Os dados utilizados neste artigo estão disponíveis no UN Comtrade, revisão 3 da Standard International Trade Classification (SITC), código 542 (medicamentos). Cada país/região é

(4) Calculado diretamente no Gephi, conforme (Blondel et al., 2008). 
representado por um nó (vértice) na rede. O valor do fluxo comercial (importação) realizado pelo país j (vértice ou nó) oriundo do país k representa o peso do relacionamento (aresta), de modo que a distribuição Force Atlas 2 considere essa variável para calcular a proximidade entre os países. Todos os valores foram deflacionados utilizando-se o Producer Price Index by industry: Pharmaceutical Preparation Manufacturing, disponibilizado pelo Federal Reserve Economic Data ${ }^{5}$.

\section{Comércio internacional de medicamentos: as métricas da Análise de Redes}

Os Grafos 1 e 2 representam o total do comércio farmacêutico praticado nos anos de 1995 e 2015. Em 1995, existem mais países próximos ao centro do Grafo 1, enquanto em 2015 (Grafo 2) há uma maior dispersão desses nós e maior concentração nas bordas.

Grafo 1

Comércio de medicamentos: 1995

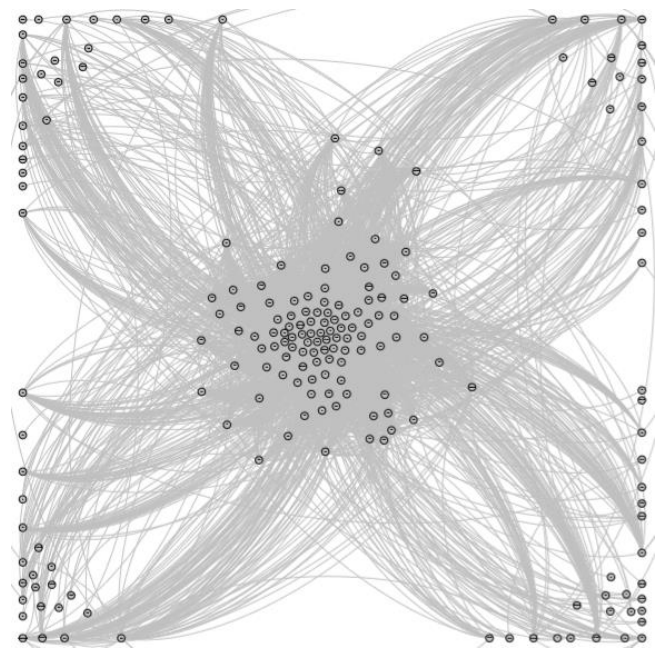

Grafo 2

Comércio de medicamentos: 2015

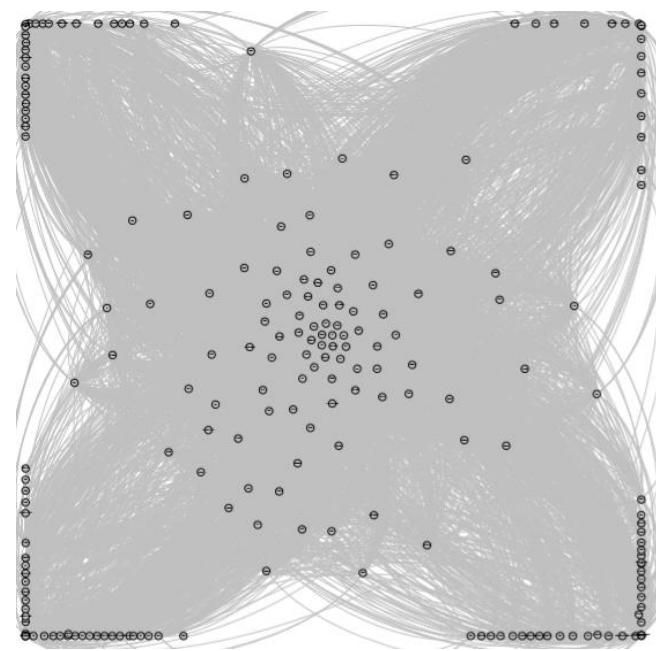

Obs.: Grafos elaborados a partir do programa Gephi versão 0.9.1. Distribuição: Force Atlas 2.

Assim, apesar do crescimento do comércio internacional, representado pelo adensamento das redes, perceptível no Grafo 2 (mais escuro), o resultado indica que a diferença entre os valores comercializados pelos países no centro do grafo e os países mais próximos da margem aumentou ao longo dos 20 anos considerados. Nos cantos dos grafos se encontram os países com valores muito baixos de comércio, o que faz com que eles fiquem aglomerados e distantes do centro. Assim, podese dizer que, em 2015, deu-se uma marginalização (perda de importância relativa) de alguns países do comércio mundial, visualizada pela maior aglomeração nos cantos da rede.

Além disso, houve aumento do número de parceiros ( $\mathrm{grau}$ ) de alguns países no centro da rede, fazendo com que estes afastem outros países, por estes últimos não possuírem comércio em magnitude suficiente para se manterem próximos ao centro da rede. A densidade (razão entre número de ligações existentes e todas as possíveis) mais elevada em 2015 aponta na mesma direção, ou seja, para a existência de um número maior de parceiros (fluxos de comércio) entre os países. Em 1995,

(5) Disponível em: https://fred.stlouisfed.org/. 
existia um total de 199 nós (países e regiões identificadas pelo Comtrade), chegando a 222 em 2015. Isso significa que países que não participavam do comércio de medicamentos em 1995 ingressaram posteriormente, o que sugere um reposicionamento de países que antes eram fechados ao comércio.

As métricas das redes, apresentadas no Gráfico 1, permitem reforçar a interpretação acima. De 1995 a 2015, a densidade da rede (o quão completa a rede está) e o grau médio dos vértices aumentaram, caracterizando elevação nas conexões comerciais entre os países. Por outro lado, o diâmetro diminuiu, de 6 em 1995 para 5 em 2015, tendo diversas vezes alcançado o valor 4 durante os 20 anos estudados. A redução do diâmetro implica em uma menor distância entre os nós mais distantes no grafo. Isso sugere que as novas conexões não foram somente estabelecidas entre países que já participavam do comércio mundial, mas também por países que ainda não estavam integrados à rede. Em outras palavras, os indicadores apontam para um processo de entrada de países que antes estavam fora da rede de comércio de medicamentos.

Outro dado importante se verifica pela diminuição do índice de modularidade entre 1995 e 2015 - a modularidade variou de 0,14 em 1995 para 0,08 em 2015. A modularidade é um valor que varia no intervalo de $[-1,1]$ e mensura a densidade das conexões existentes dentro das comunidades em comparação com as ligações existentes entre as comunidades (Blondel et al., 2008). Dessa forma, valores mais próximos a 1 revelam uma rede que apresenta forte propensão à formação de comunidades (grupos de países que possuem relação comercial mais forte entre si do que com outros que não integram o mesmo grupo). À medida que as conexões entre comunidades diferentes aumentam, os diferentes grupos passam a se unir, formando agrupamentos maiores (mais elementos), ao mesmo tempo que diminui o número de comunidades distintas.

Gráfico 1

Densidade, modularidade e grau médio da rede de comércio: 1995 a 2015

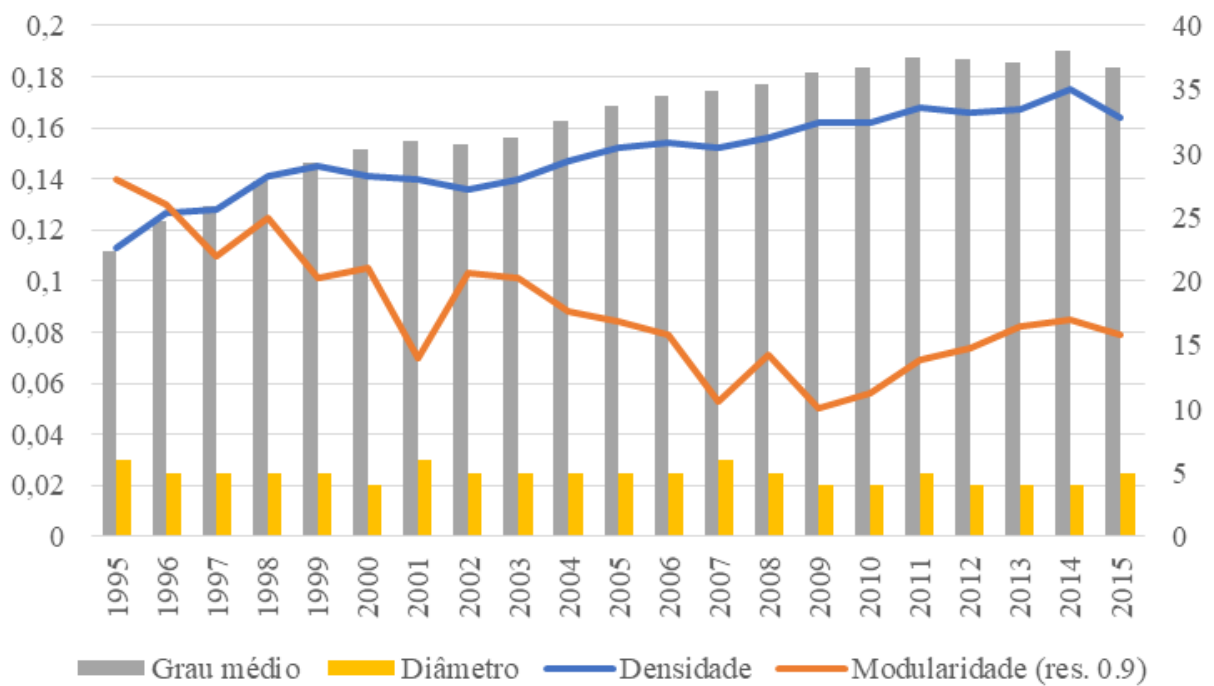

Obs.: (1) Métricas calculadas pelo Gephi versão 0.9.1.

(2) A escala à esquerda do gráfico refere-se aos indicadores Grau médio e Diâmetro (colunas) e a escala à direita diz respeito à Modularidade e Densidade (linhas). 
Em 1995, foram detectadas 6 comunidades, com a maior delas possuindo pouco mais de 50 países. Em 2015, esse número foi reduzido para 5 comunidades, com a maior possuindo mais de 100 países, sugerindo que um número maior de países está realizando importações das mesmas origens. Os países exportadores, portanto, passaram a diversificar mais seus parceiros comerciais para exportação em 2015, ampliando o número de parceiros tradicionais com os quais comercializavam em 1995. Se, por um lado, como visto no Grafo 2 (concentração nas bordas), muitos desses fluxos são pouco significativos, nota-se, conforme a Tabela 1, que o grau de saída dos países que já estavam próximos ao centro da rede aumentou consideravelmente, representando expansão do número de parceiros comerciais. Com exceção do Japão, todos os países listados ampliaram o número de destinos das suas exportações, com destaque para China e Índia. O avanço de outros países menos desenvolvidos no número de destinos de exportação também é significativo.

A variedade de parceiros no comércio de medicamentos representa a importante capacidade de lidar com regimes regulatórios distintos, ao mesmo tempo em que se seguem rigorosos padrões de qualidade estabelecidos por órgãos nacionais e internacionais. Portanto, o aumento do grau de saída de diversos países, inclusive os que não estão tão ao centro da rede, pode indicar o crescimento da padronização dos processos produtivos.

A Tabela 1 apresenta a evolução dos graus de entrada e saída (número de parceiros de importação e exportação, respectivamente), bem como os graus de entrada e saída ponderados (peso da importação e exportação com relação ao total importado/exportado no mundo) para os países que, no ano de 2015, representaram a maior parte do comercio de medicamentos. O Brasil foi incluído na lista de dezoito países para permitir uma comparação com os principais participantes da rede. Os países foram organizados de acordo com o maior valor no último ano (2015). A maior variação percentual do grau de saída observada na Tabela 1 , tanto no número de parceiros de exportação quanto no peso ponderado pelos fluxos comerciais, foi obtida pela Índia (122\% e 1534\%, respectivamente). A especialização em genéricos permitiu à Índia fortalecer sua posição no mercado de economias emergentes, o que contribuiu fortemente para o avanço no número de grau de saída. Além disso, o país também eleva sua presença nos mercados de países desenvolvidos, o que permite considerável aumento na participação do total exportado no mundo.

A Irlanda possui grau de saída consideravelmente menor, o que reflete o foco nos mercados de países desenvolvidos, mais próximos ao centro da rede de comércio. O país apresenta um aumento relativamente pequeno no número de destinos de exportação, de 106 em 1995 para 137 em 2015. Desde 1995 o país já possuía expressivo grau de saída ponderado $(0,041)$ avançando para 0,066 (60\% de variação percentual) - sétimo em origem ponderada dos fluxos comerciais. Por se concentrar em medicamentos de maior valor, esses resultados podem indicar um aprofundamento da estratégia das empresas multinacionais, ou seja, aprimoramento das bases produtivas instaladas no país para acesso privilegiado ao mercado europeu.

O Brasil permanece em uma posição de pouca relevância no comércio mundial de medicamentos, embora tenha apresentado aumento no número de destinos de exportação (de 49 em 1995 para 90 em 2015). O incremento no grau de saída ponderado, que mantém o país no final da lista dos países analisados, indica que ainda permanece pouco expressivo em termos dos valores de exportação de medicamentos, embora tenha avançado com relação ao número de parceiros comerciais. 
Kleber Alves da Silva Franculino, Rogério Gomes, Lia Hasenclever

Tabela 1

Grau de saída e entrada e graus saída e entrada ponderados por países selecionados: 1995 e 2015

\begin{tabular}{|c|c|c|c|c|c|c|c|c|c|c|c|c|c|}
\hline \multirow[b]{2}{*}{ País } & \multicolumn{3}{|c|}{ Grau de saída } & \multicolumn{3}{|c|}{ Grau de entrada } & \multicolumn{4}{|c|}{ Grau de saída ponderado } & \multicolumn{3}{|c|}{$\begin{array}{l}\text { Grau de entrada ponde- } \\
\text { rado }\end{array}$} \\
\hline & 199 & 2015 & $\begin{array}{c}\text { Var.\% } \\
1995-2015\end{array}$ & 199 & 2015 & $\begin{array}{c}\text { Var.\% } \\
1995-2015\end{array}$ & País & 1995 & 2015 & $\begin{array}{c}\text { Var.\% } \\
1995-2015 \\
\end{array}$ & 1995 & 2015 & $\begin{array}{c}\text { Var.\% } \\
1995-2015 \\
\end{array}$ \\
\hline Holanda & 117 & 206 & 76.07 & 54 & 81 & 50.00 & Alemanha & 0.145 & 0.147 & 1.36 & 0.092 & 0.073 & -20.61 \\
\hline Índia & 90 & 200 & 122.22 & 43 & 80 & 86.05 & Suíça & 0.123 & 0.104 & -15.40 & 0.044 & 0.037 & -16.64 \\
\hline Reino Unido & 119 & 195 & 63.87 & 73 & 99 & 35.62 & Bélgica & 0.053 & 0.083 & 57.63 & 0.045 & 0.060 & 33.85 \\
\hline França & 119 & 184 & 54.62 & 41 & 86 & 109.76 & EUA & 0.062 & 0.078 & 24.75 & 0.064 & 0.172 & 167.72 \\
\hline Alemanha & 121 & 181 & 49.59 & 55 & 81 & 47.27 & Reino Unido & 0.138 & 0.075 & -45.65 & 0.068 & 0.072 & 6.50 \\
\hline Bélgica & 120 & 177 & 47.50 & 69 & 71 & 2.90 & França & 0.105 & 0.070 & -33.29 & 0.073 & 0.045 & -38.91 \\
\hline Suíça & 120 & 177 & 47.50 & 50 & 81 & 62.00 & Irlanda & 0.041 & 0.066 & 60.01 & 0.011 & 0.014 & 30.09 \\
\hline China & 96 & 174 & 81.25 & 40 & 69 & 72.50 & Holanda & 0.048 & 0.051 & 6.15 & 0.058 & 0.037 & -36.16 \\
\hline EUA & 120 & 172 & 43.33 & 57 & 99 & 73.68 & Itália & 0.055 & 0.050 & -9.18 & 0.047 & 0.040 & -13.70 \\
\hline Espanha & 104 & 170 & 63.46 & 42 & 70 & 66.67 & Índia & 0.002 & 0.034 & 1534.38 & 0.001 & 0.003 & 130.14 \\
\hline Itália & 119 & 164 & 37.82 & 43 & 75 & 74.42 & Espanha & 0.014 & 0.026 & 90.63 & 0.032 & 0.033 & 2.11 \\
\hline Canadá & 104 & 143 & 37.50 & 53 & 67 & 26.42 & Canadá & 0.010 & 0.020 & 97.50 & 0.027 & 0.021 & -24.99 \\
\hline Áustria & 105 & 138 & 31.43 & 42 & 55 & 30.95 & Israel & 0.002 & 0.019 & 738.75 & 0.007 & 0.004 & -51.51 \\
\hline Irlanda & 106 & 137 & 29.25 & 39 & 58 & 48.72 & Suécia & 0.061 & 0.018 & -70.50 & 0.021 & 0.008 & -62.27 \\
\hline Dinamarca & 117 & 131 & 11.97 & 40 & 56 & 40.00 & Áustria & 0.011 & 0.015 & 33.21 & 0.026 & 0.009 & -64.92 \\
\hline Suécia & 101 & 115 & 13.86 & 39 & 48 & 23.08 & China & 0.004 & 0.010 & 182.09 & 0.005 & 0.032 & 522.60 \\
\hline Brasil & 49 & 90 & 83.67 & 45 & 60 & 33.33 & Dinamarca & 0.038 & 0.008 & -78.90 & 0.014 & 0.008 & -39.95 \\
\hline Japão & 97 & 89 & -8.25 & 36 & 49 & 36.11 & Japão & 0.018 & 0.008 & -58.84 & 0.057 & 0.039 & -30.57 \\
\hline Israel & 68 & 76 & 11.76 & 28 & 48 & 71.43 & Brasil & 0.002 & 0.003 & 82.81 & 0.009 & 0.011 & 25.97 \\
\hline
\end{tabular}

Fonte: Comtrade. Elaboração dos autores.

De maneira geral, os países desenvolvidos possuem graus de entrada consideravelmente menores que os graus de saída. Como esses países também estão no centro da rede, isso indica que eles se inserem preferencialmente na rede de comércio mundial como um número pequeno de produtores em escala global, enquanto os outros países se posicionam como destino das suas exportações.

O grau de entrada de Irlanda, Índia e Brasil também avança pouco se comparado com a evolução do grau de saída (em especial da Índia). Diferente do grau de saída ponderado, o grau de entrada ponderado do Brasil supera o da Índia, e se aproxima da Irlanda. Esse dado indica que o Brasil se insere mais fortemente na rede de comércio como importador de medicamentos.

Ao contrário de outros países avançados, os Estados Unidos aparecem com um grau de entrada ponderado superior ao grau de saída ponderado. Essa diferença era pequena no ano de 1995, mas em 2015 apresenta uma forte evolução, apesar de esse país possuir diversas empresas relevantes na indústria. Esse resultado pode indicar uma forte estratégia de investimento direto estrangeiro realizado por essas empresas, que direcionaram grandes volumes de recursos para estabelecer plantas produtivas em países como a Irlanda, como forma de permitir o ingresso facilitado no mercado europeu. 


\section{A posição do Brasil, Irlanda e Índia na rede de comércio de medicamentos}

A compreensão do quadro geral da rede de comércio de medicamentos nos permite analisar os desempenhos individuais do Brasil, da Irlanda e da Índia. Esses países foram selecionados por representarem escolhas e desenhos de políticas industriais para o setor distintas ao longo do século $\mathrm{XX}$, que acabaram por refletir na estrutura produtiva e desempenho comercial em um período posterior. Os Grafos 3 e 4 refletem a distribuição das redes de comércio, respectivamente em 1995 e 2015. As transformações observadas - e discutidas a seguir - serão interpretadas levando em conta o Quadro 2, que resume as mudanças institucionais e de políticas industriais de cada país estudado.

Em 1995, pode-se perceber (Grafo 3) a especialização da Índia em medicamentos genéricos, comercializados a preços mais baixos, com maior presença deste país nos mercados periféricos, caracterizados por menor poder aquisitivo. Uma vez que o país está presente especialmente em países menos desenvolvidos (Sri Lanka, Bangladesh, Nepal, Gana, Nigéria, entre outros), poucas conexões são visíveis, ou seja, os fluxos de exportação são mais tênues e dispersos. Esses países menores são os principais responsáveis pelo crescimento do grau de saída da Índia. Contudo, a Índia também realiza exportações para Reino Unido, França, Espanha e Suíça, o que sugere que, em 1995, este país já apresentava uma considerável capacidade competitiva no segmento dos genéricos, capaz de lhe permitir, posteriormente, a entrada em mercados mais desenvolvidos (ver Grafo 4).

A Irlanda, por sua vez, ao adotar uma estratégia de atração de multinacionais, acaba por estabelecer vínculos comerciais mais significativos com países desenvolvidos, em especial com os países-sede das empresas que direcionaram investimentos para plantas produtivas na Irlanda. Concentrando-se em medicamentos de maior valor agregado, as empresas que atuam na Irlanda exportam principalmente para o mercado europeu e para os Estados Unidos. Desse modo, diferente da Índia, a Irlanda se mantém mais afastada dos países menos desenvolvidos e mais próxima do centro da rede de comércio.

Grafo 3

Distribuição das redes de comércio do Brasil, Índia e Irlanda: 1995

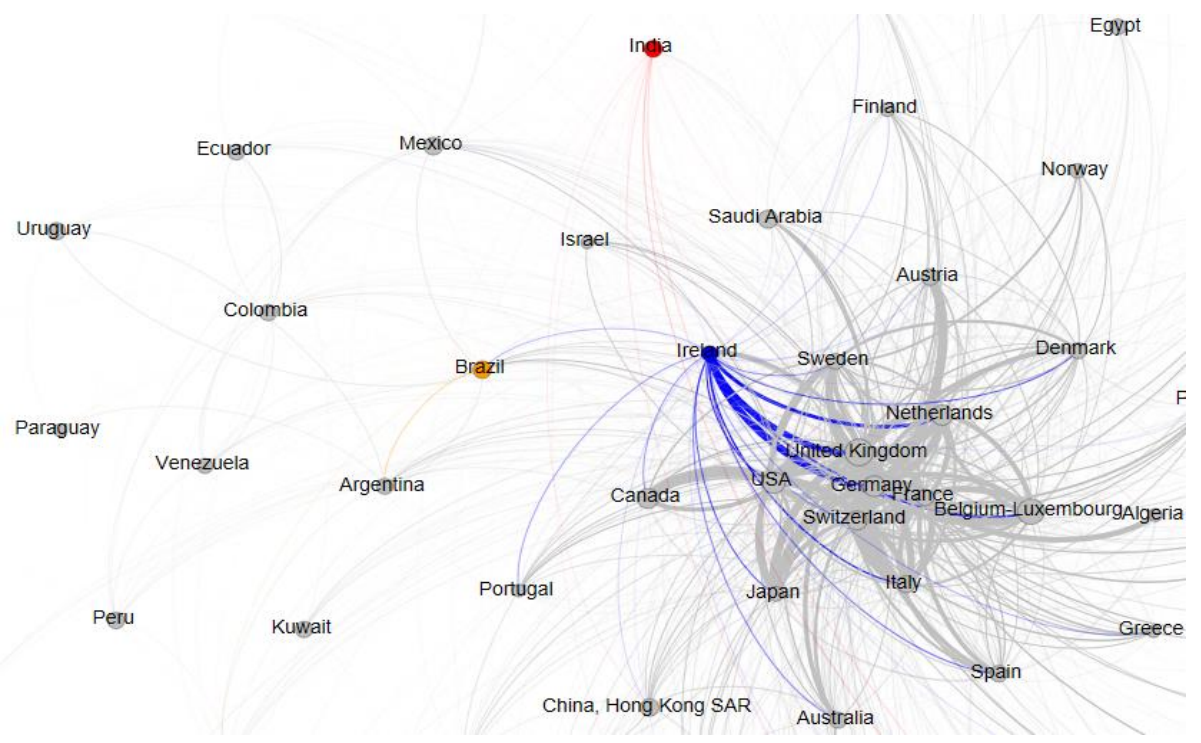


Fonte: Comtrade. Grafos elaborados pelo programa Gephi, versão 0.9.1. Distribuição: Force Atlas 2.

No caso do Brasil, verifica-se uma forte concentração das exportações no mercado regional, o que torna o país exportador para países da América Latina e importador de países europeus e dos Estados Unidos. O Brasil está situado mais próximo ao centro do que a Índia. Contudo, os déficits comerciais apresentados pelo país em medicamentos no ano de 1995, revelam que o Brasil não se aproxima do centro devido às exportações que realiza, mas sim devido ao elevado volume de importações de princípios ativos (insumos farmacêuticos ou fármacos). O processo de abertura econômica, realizado no início dos anos 1990, reforça a interpretação de que o Brasil, nesse período, acabou por se inserir no comércio internacional revelando a sua dependência produtiva e tecnológica.

O Grafo 4, relativo a 2015, apresenta mudanças consideráveis para os países analisados, em especial a Índia. Pode-se notar, em primeiro lugar, a sua maior proximidade com os países centrais, fruto do adensamento das exportações realizadas para esses países, principalmente para os Estados Unidos. O desempenho indiano nesse mercado é fruto de dois fatores conjuntos: a especialização da Índia em genéricos no mesmo período em que os Estados Unidos estavam concentrando esforços em diminuir custos com saúde (Guennif; Ramani, 2012). Além disso, a Índia aumentou as exportações para outros países, como o Reino Unido, África do Sul e Rússia. Ao longo dos anos 2000 também expirou um grande número de patentes. A Índia desenvolveu considerável competência tecnológica na produção de medicamentos genéricos e, portanto, foi capaz de aproveitar as janelas de oportunidade que surgiram.

Grafo 4

Distribuição das redes de comércio do Brasil, Índia e Irlanda: 2015

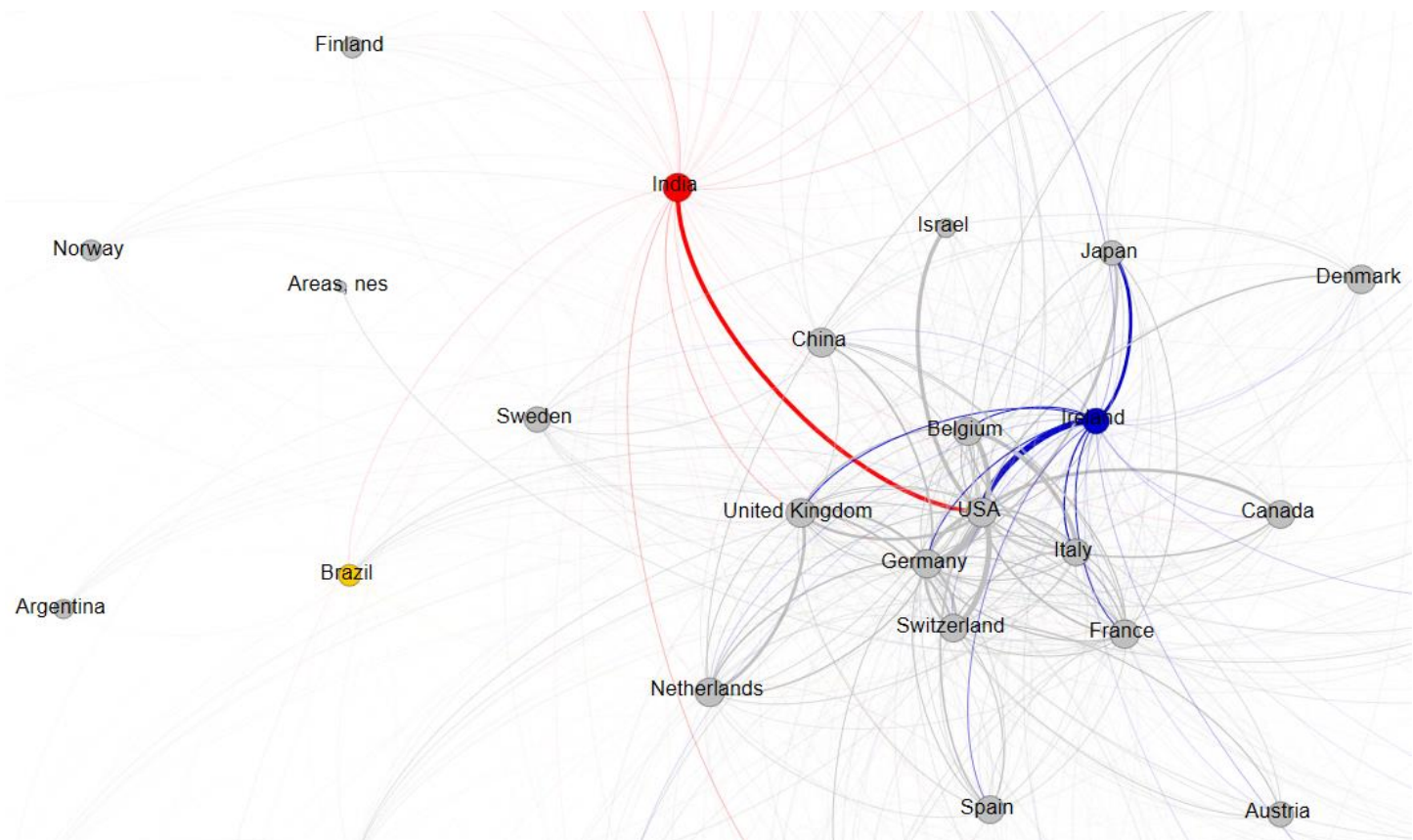

Fonte: Comtrade. Grafos elaborados pelo programa Gephi, versão 0.9.1. Distribuição: Force Atlas 2. 
A Irlanda permaneceu próxima ao centro do comércio de medicamentos, mantendo vínculos fortes principalmente com Estados Unidos, Alemanha, Reino Unido e Japão. Verifica-se, portanto, a atuação das multinacionais que, devido as políticas de atração de investimento estrangeiro conduzidas pela Irlanda, destinaram grandes investimentos para o estabelecimento e expansão das operações nesse país. Essa estratégia, diferente da adotada pela Índia, acaba por colocar os dois países em situação bastante distinta na rede: enquanto a Índia fortalece sua posição em países periféricos e em alguns países desenvolvidos, a Irlanda permanece concentrada nos mercados dos países avançados.

O Brasil permanece em uma situação periférica (distante do centro, elos tênues) em comparação com Índia e Irlanda, o que se verifica tanto pela posição que ocupa na rede (grafos 3 e 4), quanto pelo déficit comercial crescente em medicamentos. Embora tenha elevado o número de parceiros comerciais, o Brasil acaba intensificando o déficit no comércio de medicamentos. Uma observação interessante é que o principal destino de exportação de medicamentos do Brasil é a Dinamarca, que no Grafo 4 está bastante distante do Brasil. Isso significa que, apesar de ser um parceiro importante para o Brasil, trata-se de um volume de comércio irrisório no contexto da rede de comércio. O Brasil diversificou seus parceiros comerciais, mas com relação aos principais fluxos, promovidos entre países desenvolvidos, acaba permanecendo à margem do comércio de medicamentos.

\section{Considerações finais}

O estudo comparado de países que promoveram ao longo de décadas diferentes estratégias de desenvolvimento para o setor farmacêutico pôde revelar importantes características das políticas necessárias para que esse objetivo tenha sucesso. O desempenho crescentemente positivo de uma indústria específica - alvo de políticas industriais ativas - reforça a ideia de que o progresso obtido foi alcançado devido a essas intervenções, e não somente por conta da abertura comercial, embora ela também tenha tido um papel importante para explicar os resultados em termos de comércio internacional.

A perspectiva evolucionária de política industrial adotada neste artigo enfatiza o aprendizado e a inovação como elementos-chave da produtividade e do desenvolvimento. Nesse sentido, a elaboração de um ambiente propício e o estímulo ao acúmulo de competências científicas e tecnológicas se mostraram elementos centrais para o sucesso no cenário internacional, ambiente onde ocorre verdadeiramente a competição na indústria farmacêutica. Desse modo, verifica-se que o argumento de Amendola, Dosi e Papagni (1993) de que o determinante de longo prazo das pautas exportadoras e importadoras de um país possui forte relação com as competências tecnológicas desenvolvidas pelas empresas e instituições públicas e privadas, e mostra-se mais importante do que elementos como taxa de câmbio, juros e renda nacional.

Podemos perceber também que condições iniciais distintas implicam na impossibilidade de se utilizar um mesmo receituário de políticas para todos os países, uma vez que o fator institucional tanto condiciona quanto é condicionado pelas intervenções políticas elaboradas pelos governos. Portanto, o sucesso depende de diferentes arranjos e políticas regulatórias, observando-se a maneira com que essas influenciam os processos de aprendizado e seleção das empresas (Cimoli; Dosi; Stiglitz, 2009). Nesse sentido, destacam-se as diferenças apresentadas pelas políticas indianas e irlandesas. A 
Índia privilegiou a sua indústria nacional criando mecanismos de incentivo à prática de reengenharia na década de 1970. De forma diversa, a Irlanda investiu na atração de empresas multinacionais sem, no entanto, deixar de se preocupar com a consolidação de uma base de conhecimento local, por meio de políticas que procuravam vincular empresas locais às atividades das multinacionais que, para poderem usufruir das vantagens fornecidas pelos incentivos irlandeses, deveriam demandar produtos/serviços das empresas irlandesas em seu processo produtivo.

O caso do Brasil demonstra ser o que obteve menor êxito em transformar a sua indústria farmacêutica local, especialmente por conta da descontinuidade das políticas de capacitação nacional que vinha implementando durante a década de 1970 e 1980. Com a abertura econômica e o abandono das políticas industriais na década de 1990, as empresas multinacionais já instaladas no Brasil passaram a importar insumos de suas matrizes, no que foram imitadas por empresas domésticas ao avançarem na produção de genéricos na década de 2000. A partir de 2010 a importação de medicamentos cresceu também contribuindo para o déficit comercial já elevado. Desta forma, o país permaneceu conectado ao centro da rede de comércio mais por conta das importações do que pelas exportações, refletindo sua baixa competitividade exportadora.

As condições nas quais os países implementaram suas políticas, bem como a continuidade das mesmas (com a devida capacidade de adaptação/flexibilização de acordo com as mudanças no ambiente econômico), o design, modo de implementação e capacidade de avaliação contínua dos resultados obtidos se mostraram essenciais para o sucesso de uma estratégia de desenvolvimento do setor. Não é possível esperar que medidas isoladas de incentivo ao esforço inovativo, descoladas do ambiente regulatório e distante da lógica de negócios, apresentem resultados satisfatórios em termos de capacitação tecnológica. Contudo, somente a abertura econômica de um país não é suficiente para a aquisição de competência tecnológica e produtividade. Um conjunto de elementos precisa ser levado em conta para que as empresas possam se engajar em esforço de aprendizado e, com isso, apresentar condições reais de elevar sua competitividade a nível internacional.

\section{Referências bibliográficas}

AMENDOLA, G.; DOSI, G.; PAPAGNI, E. The dynamics of international competitiveness. Weltwirtschaftliches Archiv, v. 129, n. 3, p. 451-471, Sept. 1993.

ANDREONI, A. Structural learning: embedding discoveries and the dynamics of production. Structural Change and Economic Dynamics, v. 29, p. 58-74, Jun. 1, 2014.

ANVISA. Agência Nacional de Vigilância Sanitária. Disponível em: http://portal.anvisa.gov.br. Acesso em: 5 dez. 2017.

BASTIAN, E. F. As experiências chinesa e irlandesa de catching-up na década de 1990: algumas lições. Tese (Doutorado)-Universidade Federal do Rio de Janeiro, 2008.

BELL, M.; PAVITT, K. The development of technological capabilities. Technology and international competitiveness. In: HAQUE, I. U. (Ed.). Trade, technology and international competitiveness. Washington: The World Bank, 1995. cap. 4, p. 69-101. 
BLONDEL, V. D. et al. Fast unfolding of communities in large networks. Journal of Statistical Mechanics: Theory and Experiment, v. 2008, n. 10, p. P10008, Oct. 9, 2008.

CANCHUMANI, R. M. L. A produção de fármacos e medicamentos no Brasil e na Índia: uma análise comparativa (1995-2001). ICIM - International Conference on Innovation and Management, 2009.

CASTALDI, C. et al. Technological learning, policy regimes, and growth: the long-term patterns and some specificities of a 'globalized' economy. In: CIMOLI, M.; DOSI, G.; STIGLITZ, J. E. (Eds). Industrial policy and development. 1. ed. New York: Oxford University Press, 2009. cap.3, p. 39-79.

CASTELLACCI, F. Innovation and the competitiveness of industries: comparing the mainstream and the evolutionary approaches. Technological Forecasting and Social Change, v. 75, n. 7, p. 984-1006, 2008.

CHANG, H.-J. The political economy of industrial policy. 1. ed. Basingstoke: Palgrave Macmillan, 1994.

CIMOLI, M.; DOSI, G.; STIGLITZ, J. E. The political economy of capabilities accumulation: the past and future of policies for industrial development. In: CIMOLI, M.; DOSI, G.; STIGLITZ, J. E. (Eds.). Industrial policy and development. 1. ed. New York: Oxford University Press, 2009. cap. 1, p. 1-19.

COHEN, W. M.; LEVINTHAL, D. A. Absorptive capacity: a new perspective on learning and innovation. Administrative Science Quarterly, v. 35, n. 1, p. 128-152, 1990.

DE BENEDICTIS, L. et al. Network analysis of World Trade using the BACI-CEPII dataset. Global Economy Journal, v.14, n. 3-4, p. 287-343, 2014.

DOSI, G.; SOETE, L. Technological change and international trade. In: DOSI, G. et al. (Ed.). Technical change and economic theory. 1. ed. London: Pinter Publishers Limited, 1988. cap. 19, p. 401-432.

DREWS, J.; RYSER, S. Pharmaceutical innovation between scientific opportunities and economic constraints. Drug Discovery Today, v. 2, n. 9, p. 365-372, 1997.

DUNNING, J. H. What's wrong - and right - with trade theory? The International Trade Journal, v. 9 , n. 2, p. 163-202, 1995.

FAGERBERG, J. Technology and international differences in growth rates. Journal of Economic Literature, v. 32, n. 3, p. 1147-1175, 1994.

FELKER, G.; CHAUDHURI, S.; GYORGY, K. The pharmaceutical industry in India and Hungary. Washington: World Bank, 1997. (Technical Paper, n. 392).

FERRAZ, J. C.; PAULA, G. DE; KUPFER, D. Política industrial. In: KUPFER, D.; HASENCLEVER, L. (Ed.). Economia industrial: fundamentos teóricos e práticas no Brasil. Rio de Janeiro: Elsevier, 2013. cap. 24, p. 313-323.

FITZPATRICK, J. Discussion paper from Ireland on building sustainable competitive advantage in Irish industry. Dublin Fitzpatrick Associates, 2001. 
FREEMAN, C. The National System of Innovation in historical perspective. Cambridge Journal of Economics, Cambridge, p. 5-24, 1995.

GUENNIF, S.; RAMANI, S. V. Explaining divergence in catching-up in pharma between India and Brazil using the NSI framework. Research Policy, v. 41, n. 2, p. 430-441, 2012.

GUIMARÃES, E. P. Evolução das teorias de comércio internacional. Estudos em Comércio Exterior, v. 1, n. 2, p. 1-19, 1997.

HASENCLEVER, L. et al. O instituto de patentes Pipeline e o acesso a medicamentos: aspectos econômicos e jurídicos deletérios à economia da saúde. Revista de Direito Sanitário, v. 11, n. 2, p. 164,1 out. 2010 .

HASENCLEVER, L. et al. Uma análise das políticas industriais e tecnológicas entre 2003-2014 e suas implicações para o complexo industrial da saúde. In: HASENCLEVER, L. et al. (Ed.). Desafios de operação e desenvolvimento do complexo industrial da saúde. 1. ed. Rio de Janeiro: E-Papers Serviços Editoriais Ltda., 2016. cap. 3, p. 99-124.

HASENCLEVER, L.; PARANHOS, J. The development of the pharmaceutical industry in Brazil and India: technological capability and industrial development. L'emergence: Des trajectories Aux Concepts, n. November, p. 1-25, 2008.

HASENCLEVER, L.; PARANHOS, J. L'industrie pharmaceutic au Brésil et en India. Capacité technologique et développement industriel. In: PIVETEAU, A.; ROUGIER, E.; NICET-CHENAF, D. (Eds.). Émergences capitalistes aux Suds. 1. ed. Paris: Karthala, 2013. p. 88-106.

JACOMY, M. et al. ForceAtlas2, a continuous graph layout algorithm for handy network visualization designed for the Gephi software. PLOS ONE, v. 9, n. 6, p. 1-12, 2014.

KANDOGAN, Y. Topological properties of the international trade network using modified measures. The International Trade Journal, v. 00, n. 00, p. 1-25, 2017.

LEE, J. W. et al. Applications of complex networks on analysis of world trade network. Journal of Physics: Conference Series, v. 410, p. 012063, Feb. 8, 2013.

LEMME, M.; BATISTA, J. C. Política comercial. In: KUPFER, D.; HASENCLEVER, L. (Ed.). Economia industrial: fundamentos teóricos e práticas no Brasil. Rio de Janeiro: Elsevier, 2013. cap. 25, p. 325-339.

LEVINTHAL, D. Learning and Schumpeterian dynamics. In: ORGANIZATION and strategy in the evolution of the enterprise. London: Palgrave Macmillan UK, 1996. p. 27-41.

LUNDVALL, B.-A. Innovation as an interactive process: from user-producer interaction to the national system of innovation. In: DOSI, G. et al. (Ed.). Technical change and economic theory. London: Pinter Publisher, 1988. p. 349-369.

MALERBA, F.; ORSENIGO, L. Technological regimes and sectoral patterns of innovative activities. Industrial and Corporate Change, v. 6, n. 1, p. 83-118, 1997.

MARSILI, O. The anatomy and evolution of industries: technological change and industrial dynamics. Cheltenham: Edward Elgar Publishing Ltd., 2001. 
MAZZUCATO, M. The entrepreneurial state, debunking public vs. private sector myths. 1. ed. London: Anthem Press, 2013.

NASSIF, A. A economia indiana no período 1950-2004 - Da estagnação ao crescimento acelerado. Rio de Janeiro: BNDES, 2006. (Textos para Discussão, n. 107).

NELSON, R. R. National Innovation Systems: a comparative analysis. 1. ed. New York: Oxford University Press, 1993.

NELSON, R. R.; WINTER, S. G. Further analysis of search and selection. In: AN EVOLUTIONARY theory of economic change. Cambridge: The Belknap Press of Harvard University Press, 1982. cap.11, p. 246-274.

PAUS, E. Foreign investment, development, and globalization. 1. ed. New York: Palgrave Macmillan US, 2005. v. 1.

PAVITT, K. Sectoral patterns of technical change: towards a taxonomy and a theory. Research Policy, v. 13, n. 6, p. 343-373, 1984.

PENROSE, E. The theory of the growth of the firm. 4. ed. Oxford: Oxford University Press, 1959.

RAY, A. S. Aprendizagem e inovação na indústria farmacêutica indiana: o papel da IFI e outras intervenções políticas. Reciis, v. 2, n. 2, p. 74-80, 2009.

REYES, J.; SCHIAVO, S.; FAGIOLO, G. Using complex networks analysis to assess the evolution of international economic integration: the cases of East Asia and Latin America. The Journal of International Trade \& Economic Development, v. 19, n. 2, p. 215-239, 2010.

SCHUMPETER, J. A. Capitalism, socialism and democracy. 1. ed. London: Harper\& Brothers, 1942.

SUZIGAN, W.; FURTADO, J. Política industrial e desenvolvimento. Revista de Economia Política, v. 26, n. 2(102), p. 163-185, 2006.

TORRES, R. L. Capacitação tecnológica na indústria farmacêutica brasileira. Tese (Doutorado)Universidade Federal do Rio de Janeiro, 2015.

VIEIRA, V. M. da M.; OHAYON, P. Inovação em fármacos e medicamentos: estado-da-arte no Brasil e políticas de P\&D. 2006. 